\title{
Genitals as Body-Parts: Deploying Transnational and Decolonial Feminist Pedagogies Within an American Classroom to Illuminate Genital Modification Practices
}

\author{
Sanjam Ahluwalia, ${ }^{a}$ Jesse Cavalari ${ }^{b}$ \\ ${ }^{\text {a} P r o f e s s o r, ~ N o r t h e r n ~ A r i z o n a ~ U n i v e r s i t y ~}$ \\ ${ }^{b} \mathrm{PhD}$ student in History, University of Washington \\ Contingencies: A Journal of Global Pedagogy, volume 1, number 2, Fall 2021; \\ https://doi.org/10.33682/3qn1-xmnv
}

\begin{abstract}
This article is a reflection on how we developed and taught the specific topic of female genital cutting in a cross-listed Women's and Gender Studies (WGS) and History course titled, "History of Feminisms and Feminist Historiography." This topic illuminates the productive and generative work that globality and decolonial as analytical categories perform in helping students in American classrooms engage with the unfamiliar. Multimedia class materials and lectures encourage students to think critically about Western hegemony and the corporeal scripts that determine non-Western subjectivities. We argue that such decolonial and transnational feminist pedagogies train us to dispel hostility and fear towards cultural differences, inviting us instead, to explore pathways for restorative epistemic justice and forge ethnics of feminist solidarity.
\end{abstract}

Keywords: decolonizing pedagogy, female genital cutting, history of feminisms, global history, interdisciplinary pedagogy, transnational feminism.

Within history and into our contemporaneous times, different traditions of genital modifications have been read as a marker of one's gender, sexual, racial, ethnic, religious, and national identities. In the case of Africa, one form of genital modification in particular has been notoriously singled out as a trope of the continent's latent backwardness and barbarity. ${ }^{1}$ Female genital cutting (FGC), carried out differently within some parts of the African continent, is

\footnotetext{
${ }^{1}$ While Africa does not appear consistently within quotes throughout the body of this paper, in classroom lectures and discussions we used air quotes consistently and mindfully and encouraged our students to do the same. We constantly reminded ourselves through this particular module that colonial and on-going Euro-centric representational politics problematically universalizes the practice/ritual of genital cutting across the continent of Africa.
} 
represented in most dominant Euro-American texts and contexts as an uncontested reflection of a deep seated 'African,' patriarchal, and misogynistic socio-cultural landscape and as such marks the continent, its inhabitants, and their culture as uncivilized and in need of urgent Western civilizational intervention and salvation.

This paper is a reflection on how we team-taught this specific topic on genital modification in a cross-listed Women's and Gender Studies (WGS) and History course titled, "History of Feminisms and Feminist Historiography." As an interdisciplinary course with a global focus, the class is usually evenly divided between History and WGS majors. The course is chronologically and thematically designed, with nine weeks of lessons that combine lectures with moderated class discussion. Topics are organized on a weekly schedule; each week, we explore feminist debates and critiques around topics such as nationalism and 'the woman question,' suffrage and citizenship, the politics of veiling, female genital cutting, sex and reproductive politics, queer politics and homonationalism. Leaning on female genital cutting, we hope to illuminate the productive and generative work that globality and decoloniality as analytical categories perform in helping students in American classrooms engage with the unfamiliar. In doing so, the classroom also serves to render the familiar unfamiliar, as students learn to grapple with their own positionality as global citizens learning in the United States. The student body in this 300-level course has always been distinct from, say, a lower-division world history survey or an introductory WGS class. Students are somewhat self-selected; they are more advanced in their college training with greater ability to engage with complex subjects in a self-reflexive manner. The pedagogical imperatives that drive much of the content selection and classroom engagement in this course have been to trouble the dominant preconceived lexicon, 
make our imagination more flexible, foster our understanding of cultural differences, and instill an ethics of feminist solidarities across the globe. Given these emphases, the course also problematizes the history of feminisms, highlighting the global variations in feminist political organizing. Topics, themes, and readings deliberately capture the heterogeneity of feminist issues and organizing. This focus seeks to promote a recognition and an appreciation of feminist politics as always historically contingent upon local/national specificities.

Drawing upon our joint experience of teaching female genital cutting, we focus on the productive potential of deploying a transnational and decolonial feminist lens to pry open provincial thinking, inviting students in our university to introspect their underlying biases and then rethink familiar somatic cultural practices within our dominant culture. Below we highlight what is gained in teaching about this contentious topic within an American classroom. Leaning upon personal experiences, teaching materials, and class discussions, we argue that transnational feminism is extremely generative in helping us meaningfully and responsibly study cultural practices and history of far-off places and expand our imagination about the world. Moreover, in engaging with 'foreign' cultures, we can hope to get a richer, more nuanced understanding of our own heterogenous cultural landscape. A transnational feminist lens pushes open the terrain of 'our' familiar cultural landscape in ways that a singularly domestic or parochial focus is unable to deliver. An empathetic encounter with 'foreign' cultures enables the recognition of our shared humanity, illuminating our intertwined politics, histories, and economies. Discussions on this particular topic, along with others covered through the course of the semester, focus on highlighting the heterogeneous composition of the margins, whereby diverse and competing 
understandings of corporeal politics and transformational interventions shaped and continue to shape socio-cultural landscapes.

\section{Global Learning: Discussions in an Arizona Classroom on Female Genital Cutting in Parts of Africa}

Instead of easy prevarication based on misplaced liberal angst or reliance on cultural relativism, the readings and discussions in the course on female genital cutting push for a meaningful, deliberate, and close study of this difficult and uncomfortable subject. Now would be a good place to share the structure and organization of our lesson plan on FGC within our course. We drew upon a range of interdisciplinary readings and multimedia materials for this contentious topic to highlight competing perspectives. By design, our critical feminist classroom did not seek to present the 'truth,' or make any false assurances about the completion in one's thinking on the long history and impassioned global politics of FGC. The mechanics and philosophy of our teaching were organically sutured together through the week-long coverage of the topic. Required assigned materials consisted of two visual media sources and two articles by feminist scholars. ${ }^{2}$ For class lecture, we drew upon additional readings that were generously referenced and footnoted in PowerPoints, and many of these materials are referenced throughout this paper to highlight their contributions to our learning and teaching. Our coverage of FGC

\footnotetext{
${ }^{2}$ Given this is a 300 -level class, students were assigned around fifty pages of reading materials in addition to a documentary film to be screened at home in preparation for this week's discussion. The assigned readings included a 2007 essay written by Fuambai Ahmadu titled "Aint I a Woman Too?: Challenging Myths of Sexual Dysfunction in Circumcised Women" which provides an alternative, non-Western perspective on the subject. Additionally, students were asked to watch the 1993 documentary film Warrior Marks, produced by Alice Walker and Pratibha Parmar. To help unpack this deeply flawed, Eurocentric documentary, students were also asked to read Isabelle Gunning's 1998 essay "Cutting through the Obfuscation: Female Genital Surgeries in Neoimperial Culture," which presents a clear critique of the film.
} 
spanned one week, consisting of two eighty-minute classes: The first class consisted of carefully scripted lecture supported by the work of a wide range of scholars; for the second class, we wrapped up our coverage of this topic with group discussions, class reporting, and short response papers, extending an invitation to students to question through close reading and find comfort in ambivalence. We acknowledged that just as instructors we drew upon our own prolonged thinking, rethinking, and unthinking on the subject, perhaps for some students, too, the process of unpacking might stretch well beyond the duration of the institutionally determined period of 'learning' within a 16-week semester.

In introducing the subject of female genital cutting in parts of Africa, we framed the lecture and discussion around a short video reading by Beninese actor Djimon Hounsou of Binyavanga Wainaina's 2008 satirical essay, "How to write about Africa." This video provides a perfect introduction, alerting us all to the shorthand of stereotypes that are regularly used in mainstream writings and discussions about the continent of Africa. Before moving further into the complex nuances and layers of female genital cutting, students require a careful reminder of the geographical entity that our lecture, discussion, assigned readings, and films refer to: a continent made up of different countries, multiple ethnic groups, intersecting and distinct cultures, often marked by richly varied and brutal histories of European colonization from the nineteenth century onwards. This very rudimentary reminder of Africa as a distinct geographical entity, with its complex and intersecting histories, at once alerts us to our responsibilities when we study and engage 'foreign' cultures.

Certain somatomorphic interventions - for the purposes of this paper, genital modifications more specifically—are seen as legitimate, desirable, and empowering, whereas 
other forms of genital modifications practiced within locations of the Global South, especially among females, are read as culturally reprehensible and as such in need of global surveillance and interventions. Within the West, especially within instances of transsexual genital modifications, the emphasis is placed on achieving sex-gender integrity for the subject (Sullivan 107). A similar indulgent humanist logic is denied to non-Western subjects and their culturally heterogeneous practices of genital modification. The class lecture, discussions, and readings together focus on recognizing the manner in which FGC, as it is practiced in parts of Africa, is "put into discourse" (Foucault 11).

Feminist pedagogical imperatives determined the selection of our materials and the organization of class mechanics. We had students watch the video recording of Wainaina's essay (2011) along with the documentary Warrior Marks by Alice Walker and Pratibha Parmar (1993), based on the book of the same name, to help unpack competing constructions of FGC. In recognizing the subjective locations of the 'authors' of these two works, students were quick to point out the subtle and not so subtle variations in their representations of African women. While the documentary film made by an African American and a diasporic woman of color advances a form of epistemic violence, the words of a Wainaina caution us against lazy Western generalizations that shape most all colonial 'texts.' These multi-media materials help to lay bare the underlying Western imperial project of representing Africa and Africans as the absolute irreconcilable 'other,' to the Western, enlightened feminist subject. In this, they together capture masterfully the long history of the hostile Western gaze, seeking to regulate and discipline the African woman's body in order to make it conform to Eurocentric norms of embodiment, health, and sexuality. 
Teaching a topic as contentious as FGC is assisted by a historical lecture that traces the development of Western discourse about the bodies of African women. ${ }^{3}$ The historical emphasis not only illuminates the present-day relations of power on the global stage but also prepares students for the more complicated and palpable task of analyzing present-day discourse around FGC. By prefacing class discussion of modern FGC with a lecture on historical context, students are encouraged to 'think big' by drawing meaningful connections between the past and present to emphasize the ongoing influence of colonialism on our present historical moment. The lecture begins with the complicated and fascinating history of Sara Baartman, the indigenous African woman who was paraded around Europe as a sexualized oddity in the late eighteenth and early nineteenth centuries. The work of Pamela Scully and Clifton Crais serves as the foundation for a thorough lecture that locates Sara Baartman within the colonial history of racialized science; their 2011 book Sara Baartman and the Hottentot Venus portrays Baartman as a human figure caught up in the processes of early modern colonialism. Similarly, Sander Gilman’s 1985 article "Black Bodies, White Bodies: Toward an Iconography of Female Sexuality in Late Nineteenth-Century Art, Medicine, and Literature" provides an essential analysis that guides the lecture through the complicated nuances and implications of European perceptions of Baartman based solely on the sexualization of her body parts, i.e., her genitals and buttocks. Through European eyes, Baartman embodied the confluence of science, exoticism, and fetishization that defined modern Western discourse around African women's bodies for nearly two centuries. Baartman was dubbed the 'Hottentot Venus' by European publicists; they put her body on

\footnotetext{
${ }^{3}$ Aside from the materials mentioned in the above footnotes, all materials referenced were not assigned to students, but instead were used to craft the lecture presented to the students on the first day of the lesson plan for this topic.
} 
display, accentuating her private parts to make her simultaneously sexualized and ethnographic to European observers.

The gap between the nineteenth and twenty-first centuries is easily bridged with a narrative that follows the remains of Sara Baartman through time. After Baartman died in 1815, her body was cast and meticulously dissected, while her skeleton was rendered on display in the Muséum national d'Histoire naturelle in France for more than a century. Her remains were the subject of a popular South African movement that culminated with an official request from Nelson Mandela in 1994 for France to return her remains to South Africa. Encouraging students to contemplate the relevance of this late-twentieth century history probes into the differences and connections between the colonial (past) and post-colonial (present) historical moments. Baartman's history reveals the deep historical biases that continue to shape and sustain contemporary discourses about 'African' women and the practice of FGC. Namely, the colonial ethnographic gaze that fetishized Baartman's body was the historical precedent to the 'modern' gaze that placed Baartman's remains on display in a French museum. By examining the history of the Western gaze cast upon the bodies of African women, we shed necessary light on how the modern discourse around FGC has deep historical roots in colonial processes.

The lesson presents the historical framing for a more grounded understanding of histories of colonial and neo-colonial representations of African women. While the topic of FGC and much of this material and discussion is new to students, given the larger focus of the course, students are invited to rethink normative hegemonic Western representations throughout the semester. In extending this 'invitation,' we acknowledge the collective labor required to create a feminist decolonial space of learning; labor that includes reading post-colonial scholars such as 
Ahmadu, forming critiques of Western feminist work like Warrior Marks, and discussing and writing about these works critically. This decolonial feminist classroom is marked by discomfort as it fosters analytical and epistemic ruptures, whereby both the self and the other come undone as two distinct and separate entities. In rebelling against Eurocentric formulations, what simultaneously occurs is a reimagining of Western normative subjectivities and embodied practices. This pedagogical journey unfolds by students asking questions about choice of course topics and materials. We fostered deliberate and mindful feminist pedagogical practices, teaching beyond the parameters of fear, praise, or censure, to delight in examination, exploration, and rethinking from competing perspectives. Along with our students, we collectively worked to create the classroom as an inclusive, open, and non-threatening space whereby we together learned to use mindful and appropriate vocabulary in speaking and thinking about new and challenging subjects. In encouraging students to take risks in formulating questions and ideas, the classroom space promoted self-reflexivity and encouraged infidelity towards dominant and normative embodied practices such as male circumcision, a practice that many of them encountered within their immediate cultural context.

Over the years, a question that students have asked in varying articulations has been about the value of this topic to their learning, especially given it is far removed from their own lived experiences and histories. To paraphrase from one student's comments: Is our engagement with FGC in an American classroom an exercise in voyeurism? Are we being invited yet again to gaze voyeuristically at the African woman's body, particularly her genitals? On the face of it, this seemed like a fair question: Why dwell on a subject that does not have any direct bearing on our location at a university within the American academy? What distinguishes our engagement with 
this issue from the colonial feminist investments in rallying to eradicate this 'barbaric' practice? Or, are we studying this issue in solidarity with the United Nations Secretary General, Antonio Guterres, as he calls to end 'female genital mutilation,' (FGM) by $2030 ?{ }^{4}$ Or, perhaps we join in the jubilations across the 'civilized' Western world, where the mainstream media victoriously announced the legal ban on FGM in Sudan. ${ }^{5}$ We found it helpful to put these questions out in the open, not necessarily pushing the students to articulate clear responses, but more as an exercise in acknowledging the messiness of feminist transnational and decolonial inquiries. By problematizing our very engagement with the topic, we encourage the students to think of the power dynamics at play during any discussion of FGC: from liberal feminist critiques to UN proclamations, to journalistic coverage, to the classroom. Students are encouraged to think of their own positionalities as simultaneously situated citizens of the Global North and as global citizens.

As would be expected, students have expressed a multitude of responses at being introduced to the subject of genital modification. For many, this is the very first time that they are presented with this topic and invited to engage with and think about it within a public pedagogical setting of a classroom. Inevitably, there are a few students who express a knee-jerk "yuck" response to "foreign" practices (Shweder 22). In some instances, the response is underwritten with a colonial impulse to regulate deviance and expunge barbaric native cultural practices, saving the brown girl from the brown woman ${ }^{6}$ (Spivak 93). Over the two decades of teaching at a university in Arizona, Dr. Ahluwalia, one of the authors, has come to recognize a

\footnotetext{
${ }^{4}$ _www.un.org/en/observances/female-genital-mutilation-day

${ }^{5}$ www.nytimes.com/2020/04/30/world/africa/sudan-outlaws-female-genital-mutilation-.html; www.bbc.com/news/world-africa-52502489

${ }^{6}$ As readers will recognize, we have slightly revised the much-cited Spivakian formulation, for in the instance of FGC in parts of Africa, the ritual is directed mostly by women of the family and the wider community.
} 
hostility towards cultural and historical difference as constitutive during the first half of most of her courses that focus on global histories and/or transnational feminist politics. It is usually the early weeks of these courses in which students struggle with a wider global, rather than the more common national, framing. However, many shifts in perspectives and understandings do unfold as the collectivity of the classroom puts in intellectual labor to unpack and understand unfamiliar practices and histories of far off, distant places. Undeniably this labor pays off rich dividends. After we recount some additional classroom reactions, we will return to accounting the advantages of 'retraining the imagination,' that necessarily unfolds through a close and critical feminist reading of the politics of representation, especially as it relates to diverse and different cultures, histories, and peoples from across the globe.

Some students who raise doubts about the validity of studying FGC do so from a misplaced position of white liberal guilt. Given their unfamiliarity with the subject, many students retreat into analytical paralysis, where they argue that it is not their place to study or engage with different cultures, especially given their compromised neo-colonial location from within the American academy. In some instances, cultural relativism provides an easy escape from attentive unpacking and understanding of unfamiliar practices and cultures of far-off places. While this position is manifestly inadequate in realizing the pedagogic imperative of engaging cultural differences, in some measure, it is grounded in self-reflectivity rather than a quick and easy condemnation of 'foreign' cultures. It is only fair to also acknowledge that this response does not simply seek to replicate the world in the image of some fictive and normatively acceptable somatic practices, derived singularly from the dominant and more familiar Western practices. 
When presented with a carefully curated lesson plan on the subject, some students can demonstrate a keen understanding of the power dynamics that define the subject of FGC; some display neither an aversion to the topic nor the paralysis of liberal guilt, but instead a desire to understand how this practice is defined within the Western hegemon. We conclude this section with written response papers from students where they summarize and provide reflections on assigned materials. Some of these reflections reveal the efficacy of carefully curated learning materials in responsibly engaging the contentious topic of FGC. One student in their reflection noted the relevance of "designer vagina in contrast to what is considered 'female genital mutilation." This student also touched upon the important concepts of language and power in their reflection, juxtaposing how "Western women get labiaplasties to 'correct' how their vagina looks, deeming it as an empowering move to take control of your own body and to shape it how you want, while demonizing and fearmongering the idea of the 'mutilation' of the clitoris and vagina that happens in Africa." Another student demonstrated a grasp of these materials in their reflection, pointing out how "the writers [referring to Gunning and Ahmadu] argue that feminists who are anti-FGS [female genital surgeries], even if they are women of color, are imposing Eurocentric ideas of feminism and female bodily autonomy onto cultures and people who practice FGS." Although FGC only constituted one week's worth of materials for the class, the topic can be tackled in an effective way in the classroom that makes space for students to contemplate and problematize these materials to challenge preconceived notions of feminism, body politics, and Western hegemony.

Through carefully curated teaching materials along with robust interactive classroom discussions, we together explore possibilities of alternative ethical readings that transnational and 
decolonial feminist analysis make available. While acknowledging the two somewhat overlapping responses to cultural difference, where there is either a wholesale Euro-American condemnation of genital modifications as practiced among some African women, or a lingering colonial/white guilt that freezes in its encounter with the 'other,' students are invited to instead recognize the classroom as a rich, though also at times risky, contact-zone. As a feminist classroom, we work to provide a forum that enables and encourages an opportunity of 'learning to learn from below,' while simultaneously recognizing our world as centrally constituted through irretrievable heterogeneity.

\section{Beyond Dominant Western Episteme towards "Coalition of Understanding"}

As understood from within the dominant western episteme, FGC is largely represented as an abhorrent and grotesque disfigurement of the African female body. This holds true in popular and academic writings and cinematic representations, as well as 'educational' leaflets handed out by the United States Immigration and Customs Enforcement (ICE). Despite many attempts to discredit the dominant Eurocentric narrative on FGC, whereby the very terminology used to name this practice is seen as damaging the self-worth of women of African descent who live in the West, the sensibilities and discourse around this has barely shifted over the decades, if not centuries. For instance, ICE continues to indiscriminately harass brown and black women and girls who pass through American airports with propaganda and misinformed literature. ICE officers make no distinction among all visibly brown and black women and girls when they identify 'perpetrators' of, what they insist on calling, female genital mutilation, which they recognize as a 'crime.' 
As someone who is visibly marked as a brown woman, a naturalized citizen of Indian descent, Dr. Ahluwalia, one of the authors of this paper, and her daughter were subjected to interrogation about the practice as late as June 2019 at the Phoenix Sky Harbor International Airport. They were taken aside and asked about their familiarity with the practice and handed a leaflet on the subject (see fig. 1); this leaflet works as part of the teaching material to encourage student discussion of FGC and the deep investment made by Western nations to end the practice. After providing the context in which one of us received the leaflet, we displayed the material over the classroom projector and invited the students to collectively deconstruct the document through critical commentaries and questions. We facilitated their reading through simple yet critical questions about this piece of government propaganda: What is the purpose of this flyer? What role do borders play in the circulation of this material? What does this leaflet suggest about America's role in ending FGC? How does this affect the lives of women of color? Particularly concerning is the section in this leaflet that teaches the reader to recognize the signs of female genital mutilation: "The girl is from a family or a community which practices FGM; the girl's parents or relative(s) plan to take her to a country where FGM is prevalent, particularly over a school or holiday break." This leaflet fits right into the dominant Euro-American framework, in which any place east or south of Europe blurs into an undifferentiated landmass where patriarchy and misogyny reign in the name of 'culture.' Based on the (mis)information on this pamphlet-which is designed, produced, and distributed by the American government-any woman who appears to be from Africa, the Middle East, or South Asia, should be rightfully suspected of committing a crime known as female genital mutilation, which is a heinous form of child abuse. This leaflet adds a very real, contemporary dynamic to the lecture, as it demonstrates 
to students that discussions about control over black and brown women's bodies is not a thing of

the past, but very much a part of our immediate present. Operating from within this narrow

ethnocentric mindset, it appears inconceivable that women in these places could identify

gendered and sexual oppressions and organize for change within their societies. The non-West

continues to be understood as a homogenous place without history steeped in static timeless

tradition. What flows from this logic, therefore, is that if FGC is practiced among women in

Africa, then it must be practiced among all undifferentiated people of color, who are

automatically identified as always already 'foreign.'

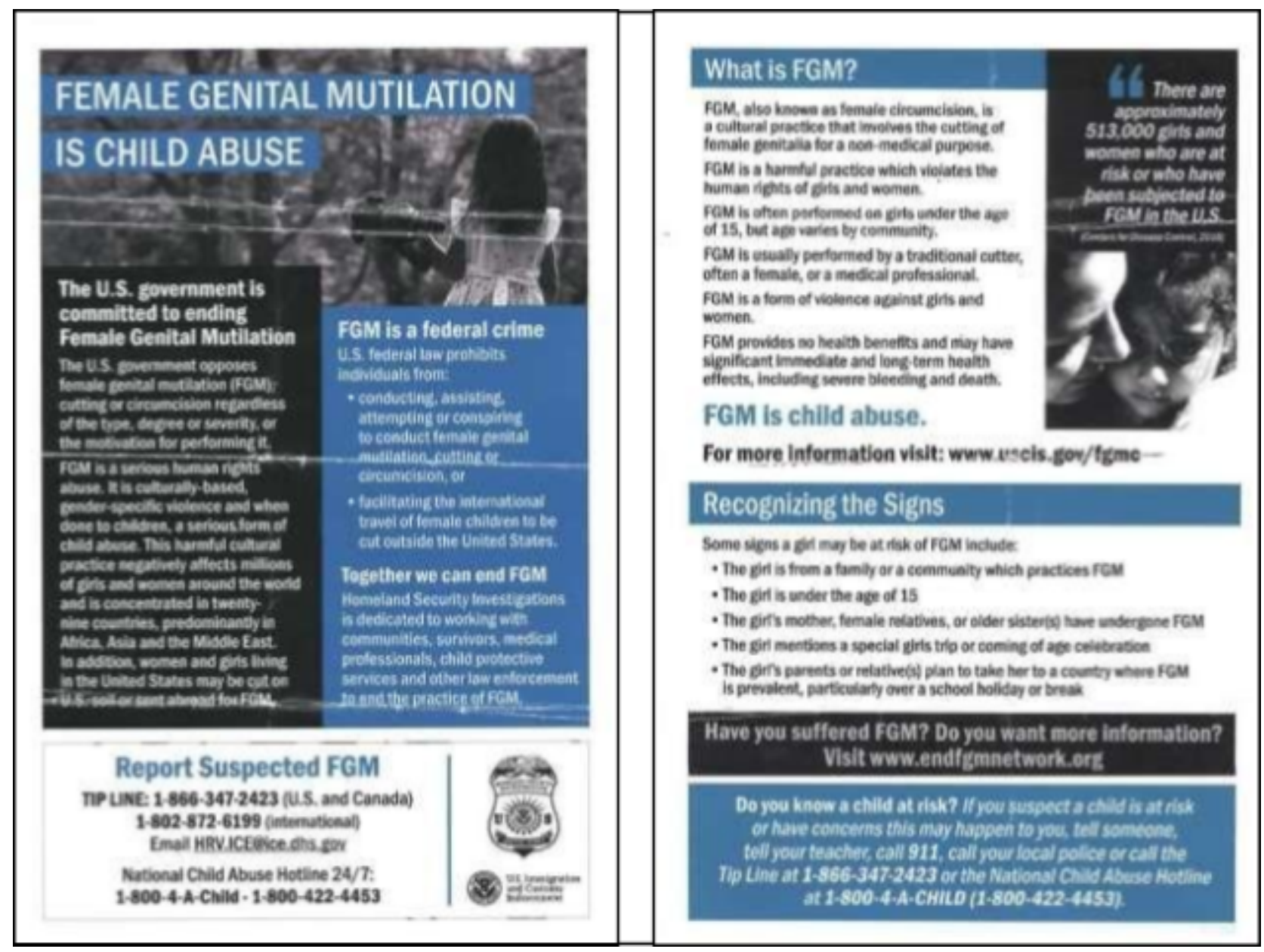


Fig. 1 Leaflet handed to Dr. Ahluwalia by Immigration and Customs Enforcement at Sky Harbor International Airport during an unwarranted interrogation while travelling to India.

The culturally biased discourse around FGC is not just limited to governments and propaganda; feminist debates on the subject are also riddled with the complications of Western-centric perspectives. A documentary film from the turn of the twentieth century brings students face to face with the concept of inherent Western hegemony and bias in American feminist discourse. Less than twenty years after Sara Baartman's remains were taken off the display at Muséum national d'Histoire naturelle, and less than ten years before her remains were repatriated to her native South Africa, the documentary Warrior Marks (1993) redefined modern colonial discourse around African women's bodies. The work of American feminist Alice Walker and British feminist Pratibha Pamar, the documentary is a call for Western intervention in halting the 'barbaric' practices of 'genital mutilation' in Africa. Alice Walker plays a central role in the film; she portrays herself as the protagonist, liberating African women from brutal patriarchy. After a lecture on Sara Baartman in the previous class and an assigned viewing of Warrior Marks, students begin to identify the troubled trajectory of modern discourse around African women's bodies. This sets them up for an in-class discussion to recognize the limitations of colonial feminist interventions on behalf of subaltern subjects.

To guide students through the critique of Western hegemony, we paired Warrior Marks with Isabelle Gunning's work that directly challenges the Western narrative presented in the film. This article not only initiates discussions about Western narratives and scripts, but also about the nature of feminism as a non-monolithic, non-linear discourse that varies wildly across localized global contexts. Class discussion can be built around Gunning's article as she critiques the western positionality of culturally dominant feminists like Walker and Parmar (Gunning 207). 
Similarly, Fuambai Ahmadu expands this critique with a theoretical framework that emphasizes the psychosexual effects African women experience through internalizing the dominant Western script about embodiment, pleasure, and subjectivities. There is an aspect of credibility to this essay that is important for teaching - Ahmadu specifically disrupts the Western power-knowledge production cycle in her research, giving voice to circumcised women in The Gambia (Ahmadu 279). Together, these articles provide a pathway for students to learn how to think critically within a global framework. Making necessary distinctions between 'Western' and 'other' voices in the film is a useful exercise for students in learning to embrace decolonized academic thought.

To counter the inherent dangers of this single story (Adichie), especially as it relates to the historically and culturally diverse practices of genital modification among girls and women across the continent of Africa, we lean upon Ahmadu's writings and interviews. As a Sierra Leonean-American anthropologist, Ahmadu presents a radically alternative narrative in her autobiographical work. Ahmadu's work allows us to widen our framing, giving voice to competing narratives that trouble the dominant Eurocentric representation of this issue across academia and popular culture, and also within some leading global agencies such as the United Nations (UN). Ahmadu highlights the damage the dominant narrative of 'mutilation' does to diasporic African women who find it impossible to experience their culturally determined embodiment in any positive manner, other than as being sexually disabled and physically mutilated (Ahmadu 301). Very simply, the introduction of Ahmadu's work generates unease and discomfort, challenging any easy reliance on outmoded sense of colonial benevolence, one that 
uncritically imagines itself as undertaking the task of "saving brown women from brown men (Spivak 93).

Our decolonial feminist classroom, through a deliberate and careful engagement with the issue of FGC, does not seek to advocate for genital modifications. We are not in the business of prescribing embodied performativities across the globe. As mentioned earlier, however, we are in the business of prying open the politics and history of Anglo-Euro-American representations of the Global South. These representations so saturate our imaginations that they leave little to no room to recognize alternative sensibilities and subjectivities that determine people's cultural expressions. Women from Africa are rarely allowed any voice in articulating their desires about embodiment, especially as it relates to the highly contentious issue of genital modifications. In the writings of Western feminists, even of women-of-color feminists such as Walker and Parmar, African women are reduced to passive victimized caricatures of themselves, rather than agentive desiring subjects. While FGC as practiced among some women in parts of the African continent is singularly frowned upon within the West, cosmetic surgeries at prohibitive costs to attain 'designer' vaginas rarely ever emote similar revulsion or humanitarian outrage to warrant 'protection' to Western elite women from global non-state agencies such as the UN. Pursuing this line of argument further, we come to recognize how FGC among some African women is seen as representing African 'tradition,' whereas the 'choice' of acquiring a designer vagina through expensive medical intervention is read as a sign of agency and self-realization. Western elite women in contrast to 'mutilated' African women are recognized as sexual subjects pursuing the approximation of 'idealized' genitals. We pause to unpack the language deployed in both instances to deconstruct the political analysis that in some instances is also presented as being 
informed by 'feminist' ideals, whereby women in two distinct global locations are differently understood as either victims in need of rescue or recognized as desiring orgasmic subjects and sexual agents.

In the classroom even as 'designer' vaginas do not appear easily credulous as a 'feminist' expression of agency, the lure of a neoliberal fantasy of 'choice' is harder to displace. While class privilege among women who opt for these surgical procedures is not lost on students, many, if not all, are epistemologically committed to celebrating the exercise of choice as centrally constitutive of rugged individualism, whereby control over one's body is an essential tenet of liberal humanism as laid out within Western Enlightenment tradition. Here is where transnational and decolonial feminism provides the necessary tools and insights to help us navigate through an intractable philosophical terrain. Instead of accepting any unitary Western framing of humanist subjects, it brings into focus those who were denied their humanity based on their intersecting location determined by class, race, ethnicity, gender, sexuality, and religion. How does a designer vagina operate as an expression of free choice within a heteropatriarchal and misogynistic culture, one which is obsessed to the point of distraction with women's bodies and their measure of experiencing pleasure? (Ahluwalia) Who determines the physiology and appearances of an idealized vagina, and on what basis? Operating as we do within a hegemonic heterosexual economy of embodiment and sexuality, the exercise of free choice by women appears hopelessly compromised, especially in this instance, where women rely on 'surgical' mutilation to approximate idealized and extravagantly feminine vaginas. As an analytical maneuver, when we displace the articulation of FGC onto the practice of designer vaginas, then the problematic 
framing of African women and their cultural embodiment becomes immediately apparent and we are embarrassed and forced to check our arrogant, neo-colonial gaze.

The topic of genital cutting is not and cannot be limited to the ways in which the Western hegemon explicitly casts African practices of FGC as barbaric. Problematizing female genital cutting also facilitates a feminist interrogation of the dominant culture framing of male genital cutting (MGC) within the U.S. and other parts of the globe. MGC, while performed on neonate infants, has rarely been framed in the language of negative evaluative descriptors such as mutilation, unlike the practice of FGC in Africa. MGC has been normalized as a medical procedure and framed as ensuring men's sexual health (Fox and Thomson). Male infants in the United States, specifically, are subjected to some of the highest rates of circumcision on the planet; in this, the U.S. is an outlier in the western world, with a rate between 80 and 90 percent, while most European countries circumcise around $20 \%$ of their male children. On a global scale, in 2007 the World Health Organization and the Joint United Nations Programme on HIV/AIDS estimated that $30 \%$ of male children are circumcised, of whom an estimated two-thirds are Muslim children. These numbers add a necessary layer to the problematization of FGC. How is it that the United States can be comparable to many African and Middle Eastern countries in the practice of male circumcision, while simultaneously putting material investment into the global crusade against female circumcision as practiced in parts of Africa? Despite the high prevalence of MGC, the somatic-sexual integrity and wholeness of circumcised Western white male bodies is rarely ever in doubt. This inherent contradiction reveals the ways in which these very different discourses operate to create the West and its 'other.' That is, the way we frame our discussions about male circumcision suggests that it is medically acceptable and desirable and, as such, is 
removed from the 'barbaric cultural practice' of FGC. In inviting students to contemplate this disconnect, we can render the familiar quite unfamiliar.

Integrating an intentional and thorough lesson plan for FGC into the curriculum of a social science/humanities class also provides students with the opportunity to engage with the idea of biopower as a theoretical framework. The comparison between the 'normal' types of FGC in the West - designer vaginas, specifically—and the 'backward' types of FGC in parts of Africa lends itself to a discussion on unpacking the workings of power. Sara Johnsdotter and Birgitta Essén eloquently explain how "[g]enital modifications take place in a sphere where biology, medicine and culture are intertwined" (30). Unpacking this sentiment in the classroom encourages students to think critically about what it looks like to responsibly engage with global FGC practices. Moreover, S. Rodrigues aptly points out that the purpose of vaginal cosmetic surgeries in the west is to "discipline individual bodies, demarcate and regulate a population defined by its vulval aesthetics, and ultimately create the optimal, "biopolitical vagina" (778). Given these nuances, pedagogically FGC can provide feminist educators with fertile ground on which to build discussions about biopolitics and power, capture the value in pursuing non-monolithic framings of feminist discourses, and expose the necessity of recognizing the deep and rich historical linkages between the past and present.

\section{Post-Script}

What is gained through our engagement with cultures, histories, politics, and peoples far removed from our experiences? A clever though somewhat flippant response to the question about why engage FGC within an American classroom is that true learning extends beyond mere self-indulgent navel gazing, even as we inhabit a deeply individualistic capitalist social order. On 
a more serious note, as the discussion above makes apparent, much is to be gained through a careful and respectful curious engagement with the 'other.' This engagement at once disrupts stable and easy colonial tropes and judgements leveled against 'foreign' cultures, enabling us to nimbly pivot our framing to restore shared imperfect humanity across artificially constructed national borders. In undoing the radical alterity of women in the Global South, we simultaneously acquire new perspectives to problematize embodied practices among some elite women, men, and transgender subjects in the West. A genuine opening to the 'other' illuminates the illusionary insularity of the modern Western subject, making our imaginations that much more nimble and enabling our appreciation of diversity, locally and globally. In calling into question the ahistorical construct of the African woman as always already victimized, the fault lines within the epistemic and political relations of power that universalize and normalize a unitary Western subject position as essentially autonomous and self-determined simultaneously rupture. Moreover, this engagement equally enhances our ability to recognize and appreciate the mutually tangled histories and traditions that have constituted the global world we collectively inhabit, troubling the false binaries that divide the Western self from the non-Western other. Even as we have focused on a specific topic, the generative potential of decolonial pedagogic labor that fosters cultural competencies and critical thinking, along with an invitation to disobey normative cultural formulations, could be widely applicable to teaching across the humanities and social sciences.

Cultural competencies gained through habits of active cognitive training may temporarily require learners to navigate spaces of discomfort and perhaps self-alienation, especially as we are forced to recognize and encounter many overlapping similarities across our rich differences. As 
is evident from the discussion above, destabilizing the partisan distortions of Western episteme bestows a richness to our understanding of the histories and practices of genital modifications and embodied subjectivities across the world. Decolonial and transnational feminist pedagogies train us to dispel hostility and fear towards cultural differences, inviting us instead to explore pathways for restorative epistemic justice and forge ethics of feminist solidarity. These pedagogies extend an invitation for exploring the parameters of what Maria Lugones referred to as world travelling to build coalitions at the point of differences, where multiplicities are never reduced (755).

Sanjam Ahluwalia is a Professor in the Women's and Gender Studies Program and Department of History at Northern Arizona University (NAU). She currently serves as the Director of Women's and Gender Studies Program at NAU. Her research interests are in the fields of sexuality studies, and women/gender histories, with an emphasis on reproductive health and sexology. Her book Reproductive Restraints: History of Birth Control in India, 1877-1947, was co-published by Illinois University Press, and Permanent Black, New Delhi. She is currently completing her book manuscript on the global history of sexology, titled Sex from the Margins: Global History of Sexology from India, 1930s-1950s. Dr. Ahluwalia serves on the Editorial Board for The Historian, published from Lahore, Pakistan. She also serves as a consultant for the journal, Feminist Studies. 
Jesse Cavalari is a $\mathrm{PhD}$ student at the University of Washington in Seattle where he studies the history of medicine and environmental history in Latin America and the Caribbean. He earned his MA in history, and a graduate certificate in Women's and Gender Studies from Northern Arizona University. 


\section{Works Cited}

Adichie, Chimamanda Ngozi. “The Danger of a Single Story.” YouTube, uploaded by TED, 7 October 2009, www.youtube.com/watch?v=D9Ihs241zeg. Accessed 3 August 2020.

Ahluwalia, Sanjam. “'Tyranny of Orgasm’: Global Governance of Sexuality from Bombay: 1930s-1950s.” Global History of Sexual Sciences, 1880-1960, edited by Veronika

Fuechtner, Douglas Haynes, and Ryan Jones, Oxford University Press, 2018, pp. 353-73.

Ahmadu, Fuambai. “'Ain’t I a Woman Too?': Challenging Myths of Sexual Dysfunction in Circumcised Women.” Transcultural Bodies: Female Genital Cutting in Global Context, edited by Ylva Hernlund and Bettina Shell-Duncan, Rutgers University Press, 2007, pp. 278-310.

Ahmed, Leila. A Border Passage: From Cairo to America - a Woman's Journey. Straus and Giroux, 1999.

Crais, Clifton, and Pamela Scully. Sara Baartman and the Hottentot Venus: A Ghost Story and a Biography. Princeton University Press, 2011.

Foucault, Michel. The History of Sexuality. Pantheon Books, 1978.

Fox, Marie, and Michael Thomson. "Foreskin is a Feminist Issue." Australian Feminist Studies, vol. 12 , no. 60,2020 , pp. $195-210$.

Gilman, Sander L. "Black Bodies, White Bodies: Toward an Iconography of Female Sexuality in Late Nineteenth-Century Art, Medicine, and Literature." Critical Inquiry, vol. 12, no. 1, 1985, pp. 204-242.

Gopal, Priyamvada. "On Decolonisation and the University." Textual Practice, vol. 35, no. 6, 2021, pp. 873-99. 
Gunning, Isabelle. "Cutting through the Obfuscation: Female Genital Surgeries in Neoimperial Culture." Talking Visions: Multicultural Feminism in Transnational Age, edited by Ella Shohat, New Museum of Contemporary Art, 1998, pp. 203-24.

Johnsdotter, Sara \& Birgitta Essén. "Genitals and Ethnicity: The Politics of Genital Modifications." Reproductive Health Matters, vol. 18, no. 35, 2010, pp. 29-27.

Lugones, María. "Playfulness, 'World'- Travelling, and Loving Perception.” Making Face, Making Soul Haciendo Caras: Creative and Critical Perspectives of Feminists of Color, edited by Gloria Anzaldúa, Aunt Lute Books, 1990, pp. 390- 402.

---. “Towards a Decolonial Feminism.” Hypatia, vol. 24, no. 4, 2010, pp. 742-59.

Rodrigues, Sara. "From Vaginal Exception to Exceptional Vagina: The Biopolitics of Female Genital Cosmetic Surgery." Sexualities London, vol. 15, no. 7, 2012, pp. 778-94.

Shweder, Richard A. “What About 'Female Genital Mutilation'? and Why Understanding Culture Matters in the First Place." Engaging in Cultural Differences: The Multicultural Challenge in Liberal Democracies, edited by Richard A. Shweder, Martha Minow, and Hazel Rose Markus, Russell Sage Foundation Press, 2002.

Spivak, Gayatri Chakravorty. "Can the Subaltern Speak?” Colonial Discourse and Post-Colonial Theory: A Reader, edited by Patrick Williams and Laura Chrisman, Harvester Wheatsheaf, 1993.

Sullivan, Nikki. "The Role of Medicine in the (Trans)Formation of 'Wrong' Bodies." Body \& Society, vol. 14, no. 1, 2008, pp. 105-16.

Warrior Marks, directed by Alice Walker, Pratibha Parmar, Nancy Schiesari, and Richelle Donigan, Women Make Movies, 1993. 
Wainaina, Binyavanga. How to Write About Africa. Kwani Trust, 2008.

Wainaina, Binyavanga. "How To Write About Africa” YouTube, uploaded by Michael Kirkpatrick, performed by Djimon Hounsou, 27 October 2011, www.youtube.com/watch?v=BYVvEa3dSeU. Accessed 3 August 2020.

World Health Organization and Joint United Nations Programme on HIV/AIDS. Male Circumcision: Global Trends and Determinants of Prevalence, Safety and Acceptability, WHO Press, 2007, apps.who.int/iris/bitstream/handle/10665/43749/9789241596169_eng.pdf;jsessionid=8F7 B55C141B9459E336D85E93D88F41C?sequence=1 Accessed 3 August 2020.

Wynter, Sylvia. “‘Genital Mutilation’ or 'Symbolic Birth?’ Female Circumcision, Lost Origins, and the Aculturalism of Feminist/Western Thought." Case Western Review Law Review, vol. 47, no. 2, 1997, pp. 501-52. 